\title{
Effects of Temperature and Humidity on COVID-19 Transmission in California, US: A Time-Series Study
}

\section{Lanlan Fang}

Anhui Medical University

\section{Dingjian Wang}

Anhui Medical University

Guixia Pan ( $\nabla$ pgxkd@163.com )

Anhui Medical University https://orcid.org/0000-0002-1278-8486

\section{Research}

Keywords: COVID-19, temperature, humidity, DLNM.

Posted Date: September 4th, 2020

DOI: https://doi.org/10.21203/rs.3.rs-64366/v1

License: (1) This work is licensed under a Creative Commons Attribution 4.0 International License. Read Full License 


\section{Effects of temperature and humidity on COVID-19} transmission in California, US: A time-series study

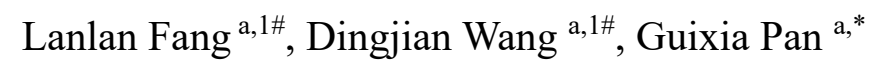

${ }^{a}$ Department of Epidemiology and Biostatistics, School of Public Health, Anhui

Medical University, 81 Meishan Road, Hefei, Anhui 230032, China.

\# Lanlan Fang and Dingjian Wang contributed equally to this work and should be

considered co-first authors. fanglanlanxi@163.com; Wangdingiian666@163.com.

* Correspondence: pgxkd@163.com. 
49

\section{Abstract}

Background: Previous researches inferred that high temperatures and high humidity might weaken COVID-19 transmission. However, with the warming weather coming, the COVID-19 pandemic is still intensifying.

Methods: This study aims to evaluate the associations between daily temperature, relative humidity, and COVID-19 cases using the Distributed Lag Non-linear Model (DLNM) from Jan $27^{\text {th }}$ to July $15^{\text {th }}, 2020$, in California, US.

Results: There was a statistically significant difference between COVID-19 and temperature from $6{ }^{\circ} \mathrm{C}$ to $9{ }^{\circ} \mathrm{C}$, relative humidity from $80 \%$ to $98 \%$. It increased the risk of $95.4 \%$ at $6{ }^{\circ} \mathrm{C}(\mathrm{RR}: 1.954$; CI: $1.032-3.701)$. It increased the risk of $70.3 \%$ when the humidity was $98 \%$ (RR: 1.703 , CI: $1.049-2.765$ ). At low temperature group, it increased the risk of $46.3 \%(\mathrm{RR}=1.463,95 \% \mathrm{CI}: 1.054-2.030)$ on lag $0-4$ days. At high humidity group, it increased the risk of $42.3 \%(\mathrm{RR}=1.423,95 \% \mathrm{CI}: 1.070-1.892)$ on lag 0-6 days.

Conclusions: We found that low temperature and high humidity were the risky factors of COVID-19 transmission, and higher temperature and lower humidity had no effect on the transmission of COVID-19, which indicated that it might not slow down due to weather factors in summer in the Mediterranean climate.

Keywords: COVID-19, temperature, humidity, DLNM. 


\section{Introduction}

COVID-19 is caused by the severe acute respiratory syndrome coronavirus 2 (SARS-CoV-2), a novel coronavirus. The World Health Organization (WHO) categorized COVID-19 as a pandemic on March 11, 2020 (https://www.who.int/ dg/speeches/detail/who-director-general-s-opening-remarks-at-the-media-briefing-oncovid-19---11-march-2020). Due to the high contiguousness and widespread, the COVID-19 pandemic has been the most serious global crisis, affecting almost all countries on our planet since the World War-II [1]. Globally, as of July $9^{\text {th }}$, 2020, there have been 11,874,226 confirmed cases of COVID-19, including 545,4 81 deaths, reported to WHO (https://www.who.int/dg/speeches/detail/who-directorgeneral-opening-remarks-at-the-member-state-briefing-on-the-covid-19-pandemic-ev aluation---9-july-2020). The pandemic is still growing in most countries and is far from under control.

Many studies suggested that environmental factors were risk factors for acute infectious diseases. For instance, a study based on Hong Kong, Guangzhou, Beijing, and Taiyuan indicated that the outbreaks of SARS were significantly related to temperature [2]. Another study in US cities indicated that humidity was the best predictor of COVID-19 transmission [3].

The relationship between environmental factors and COVID-19 has been a hot topic of great concern by scholars all over the world since the emergence of COVID19. Temperature and humidity played a significant role in the seasonal spread of coronaviruses [4]. A laboratory review suggested that SARS-CoV-2 can survive longer 
in environments with lower temperature and lower relative humidity [5]. Another laboratory study also reported that the viability of coronaviruses reduced rapidly when the temperature or relative humidity increased [6]. Most epidemiological studies [3,79] also suggested that the weather with low temperature and low humidity likely favored the transmission of COVID-19. However, a Brazilian study [10] showed that higher mean temperature and average relative humidity favored the COVID-19 transmission, differently from reports from coldest countries or periods under cool temperatures.

People generally believe the hypothesis that coronaviruses are not easily transmitted in hot and humid conditions [11]. In 2005, Lin et al. found that the risk of increased daily incidence of SARS in lower temperatures was 18.18 -fold (95\% CI: 5.68.8) higher than that in higher temperatures in Hong Kong [12]. Like the SARS, its epidemic was gradually faded with the warming weather coming and was ended in July $2003[2,13,14]$.

Liu et al. indicated that the COVID-19 might gradually ease as a result of rising temperatures in the coming months [8]. However, another study having the same research background showed that mean temperature and COVID-19 confirmed cases was an approximately positive linear relationship in the range of $<3{ }^{\circ} \mathrm{C}$ and became flat above $3{ }^{\circ} \mathrm{C}$ and COVID-19 may not perish of itself without any public health interventions when the weather becomes warmer [15]. Bashir et al. also reported similar findings for COVID-19 cases in New York, US [16]. Auler et al. concluded that high temperature and humidity did not reduce the transmission of COVID-19 in tropical 
regions [10]. Therefore, there is currently no consensus on the impact of temperature and humidity on the transmission of COVID-19.

The temperature is gradually warming, but the global epidemic is still intensifying, breaking through 10 million, and there is no downward trend. Due to the severe situation and the heterogeneity of different regional backgrounds, the relationship between temperature, humidity, and COVID-19 deserves further discussion.

California is located on the west coast of the United States, with an area of about 410,000 square kilometers, a population of about 37.69 million, and a population density of about 86 people per square kilometer. California has been one of the hardesthit states since the outbreak of COVID-19 in the United States. As of July $26^{\text {th }}$, California ranked first in the United States with more than 440,000 cases. California has a Mediterranean climate, with high temperature and low humidity in summer and low temperature and high humidity in winter.

In this study, we explored the effects of temperature and humidity on COVID-19 transmission in California, US during the period Jan $27^{\text {th }}-J u l y ~ 15^{\text {th }}, 2020$. We investigated the effects of daily temperature, daily relative humidity on the daily new confirmed COVID-19 cases using the Distributed Lag Non-linear Model (DLNM), and investigated the delayed effects of specific temperature and humidity. This will contribute to investigating the association between meteorological variables and COVID-19 cases in the Mediterranean region. It had a longer research period than previous reports. 


\section{Materials and methods}

\subsection{COVID-19 data}

As of July $15^{\text {th }}, 2020$, data on daily new confirmed COVID-19 cases were collected from the Johns Hopkins Center for Systems Science and Engineering repository (https://github.com/CSSEGISandData/COVID-19). Since uncertain and anonymous data on the incidence of cases were obtained from a publicly accessible data website, this study did not involve the consent of the participants, and there was no need for institutional review.

\subsection{Meteorological data}

The monitoring station, SACRAMENTO MCCLELLAN AFB, CA, US was used. Sacramento, the capital of California, is located between $38^{\circ} 34^{\prime} \mathrm{N}$ and $121^{\circ} 28^{\prime} \mathrm{E}$. Daily meteorological data, including daily average temperature, average dew point, and average wind speed, were obtained from the National Oceanic and Atmospheric Administration Center (https://www.ncei.noaa.gov/access/search/data-search/globalsummary-of-the-day).

\subsection{Calculation of relative humidity}

The relative humidity is the ratio of the actual water vapor pressure to the saturated water vapor pressure at the current temperature, calculated using the following formula:

$$
R H=\frac{E}{E_{W}} \times 100 \%
$$

$R H$ represents the relative humidity. $E(\mathrm{hPa})$ contributes to the air vapor pressure at temperature $t\left({ }^{\circ} \mathrm{C}\right) . E w(\mathrm{hPa})$ gives the saturated vapor pressure of the pure horizontal liquid surface at the dry bulb temperature $t\left({ }^{\circ} \mathrm{C}\right)$. The dew point is the temperature at 
which the air must be cooled to become saturated with water vapor. The dew point temperature can be used to calculate the actual vapor pressure $E$, and the actual temperature can be used to calculate the saturated vapor pressure using the Magnus formula [17]:

$$
E=E_{0} \times e^{\frac{A t}{B+t}}
$$

where $E_{0}$ represents the saturated vapor pressure at the reference temperature $\mathrm{T}_{0}$ $(273.15 \mathrm{~K}$ ) which equals $6.11 \mathrm{Mb} . A$ is a constant of 17.43 and $B$ is a constant of 240.73 . $t\left({ }^{\circ} \mathrm{C}\right)$ is the actual temperature or dew point.

\subsection{Statistical analysis}

We conducted the time-series regression analysis to find associations between daily temperature, relative humidity, and daily new confirmed cases of COVID-19. As the response variable was composed of daily new counts, we used the quasi-Poisson regression model, which can capture over dispersion often present in count data [18]. We used the DLNM to capture non-linear relationships and lagged associations with the application of the "cross-basis" function (a two-dimensional basis function) [19]. The model is as follows:

$$
\mathrm{y}_{t} \sim \operatorname{quasi-Poisson}\left(\mu_{t}\right)
$$

$$
\begin{aligned}
& \log \left(\mu_{t}\right)=\alpha+\beta_{1} c b . T e m p+n s(R H, 3)+n s(\text { WDSP, 3) }+n s(\text { time }, 3) \\
& \log \left(\mu_{t}\right)=\alpha+\beta_{1} c b . R H+n s(\text { Temp }, 3)+n s(\text { WDSP, 3) }+n s(\text { time }, 3)
\end{aligned}
$$

In the model, $y_{t}$ was the counts of daily new confirmed cases of COVID-19 for day $t$ (added one to avoid taking the logarithm of zeros [20]. $\alpha$ was the intercept. Temp represented daily average temperature. $\beta_{1}, \beta_{2}$ were the vector of regression 
coefficients for $c b . T e m p, c b . R H$, which were the cross-basis matrix of temperature, relative humidity. The maximum lag day was set as 7 days, which was based on previous studies [3]. We allowed for non-linear relationships by using a natural cubic spline with 3 degrees of freedom (df), and the lagged effects were modeled using a natural cubic spline with an intercept and three internal knots placed at equally-spaced log-values. ns () is the natural cubic spline. WDSP represented average wind speed, 3 df was used to adjust for average wind speed. Besides, time was used as a variable to control the long-term trend effect using $3 \mathrm{df}$.

According to the three-dimension plot between temperature (Fig. 2a), relative humidity (Fig. 3a), and COVID-19 cases, determine a temperature of $20^{\circ} \mathrm{C}$ and relative humidity of $60 \%$ as reference values. Set the 5th (defined as low), 25th (defined as lower), 75th (defined as higher), and 95th percentile (defined as high) of daily temperature and relative humidity as different groups to study delayed effects of specific temperature and humidity on daily new confirmed COVID-19 cases.

All the statistical analyses were performed in R 3.6.2 software with the 'dlnm' and 'splines' packages. The two-sided P-value $<0.05$ was considered statistically significant.

\subsection{Sensitivity analysis}

To evaluate the robustness of the model, a sensitivity analysis was performed using the assessment of several dfs: temperature $(\mathrm{df}=2,4)$, relative humidity $(\mathrm{df}=2,4)$, wind speed $(\mathrm{df}=2,4)$, time $(\mathrm{df}=2,4)$. The maximum lag day of temperature, relative humidity was also set to 6,8 to examine the sensitivity of the effects. 


\section{Results}

\subsection{Characteristics of COVID-19 and meteorological variables}

The characteristics of COVID-19 and meteorological variables were shown in

Table 1. During the study period from Jan $27^{\text {th }}$ to July $15^{\text {th }}, 2020$ (171 days), a total of 355285 confirmed cases were included in California, US. The number of daily new cases during this period ranged from 0 to 12978 (mean $\pm \mathrm{SD}, 2076 \pm 2604$, median 1372). The temperature gradually increased during the observation period. The temperature levels ranged from $6.33{ }^{\circ} \mathrm{C}$ to $30.72{ }^{\circ} \mathrm{C}($ mean $\pm \mathrm{SD}, 17.53 \pm 6.13$, median 16.39). The relative humidity gradually decreased during the observation period. The relative humidity levels ranged from $23 \%$ to $100 \%$ (mean $\pm \mathrm{SD}, 55 \% \pm 0.19$, median 53\%). Fig. 1 (a), (b), (c) showed trends for daily new confirmed cases, temperature, and relative humidity respectively.

Table 1. characteristics of COVID-19 and meteorological variables 2020.1.27-2020.7.15.

\begin{tabular}{|c|c|c|c|c|c|c|c|c|c|}
\hline \multirow[t]{2}{*}{ Group } & \multirow[t]{2}{*}{ Mean } & \multirow[t]{2}{*}{ SD } & \multirow[t]{2}{*}{ Min } & \multirow[t]{2}{*}{$\operatorname{Max}$} & \multirow[t]{2}{*}{ Median } & \multicolumn{4}{|c|}{ Frequency distribution } \\
\hline & & & & & & P5 & $\mathrm{P} 25$ & P75 & P95 \\
\hline Cases & 2076 & 2604 & 1 & 12978 & 1372 & 1 & 17 & 2783 & 8256 \\
\hline Temp & 17.53 & 6.13 & 6.33 & 30.72 & 16.39 & 9.42 & 12.06 & 22.34 & 27.951 \\
\hline RH & $55 \%$ & 0.19 & $23 \%$ & $100 \%$ & $53 \%$ & $29 \%$ & $39.5 \%$ & $69 \%$ & $89 \%$ \\
\hline WDSP & 6.28 & 2.80 & 0.80 & 15.70 & 6.00 & 2.16 & 4.30 & 8.20 & 11.18 \\
\hline
\end{tabular}

Cases, daily new cases of COVID-19; SD, standard deviation; Min, minimum; Max, maximum. P5, P25, P75, P95: the 5th percentile, the 25th percentile, the 75th percentile, the 95th percentile. 
new confirmed cases (a)
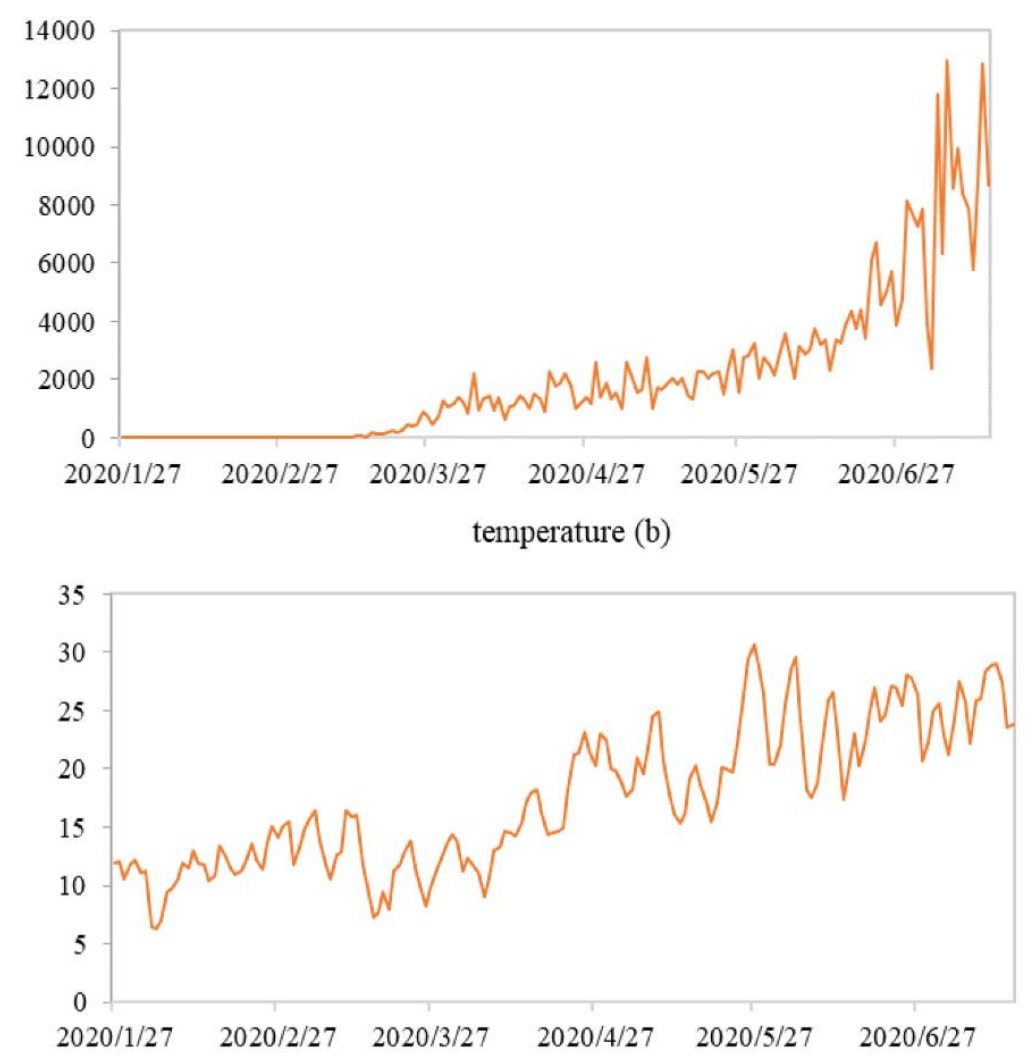

relative humidity (c)

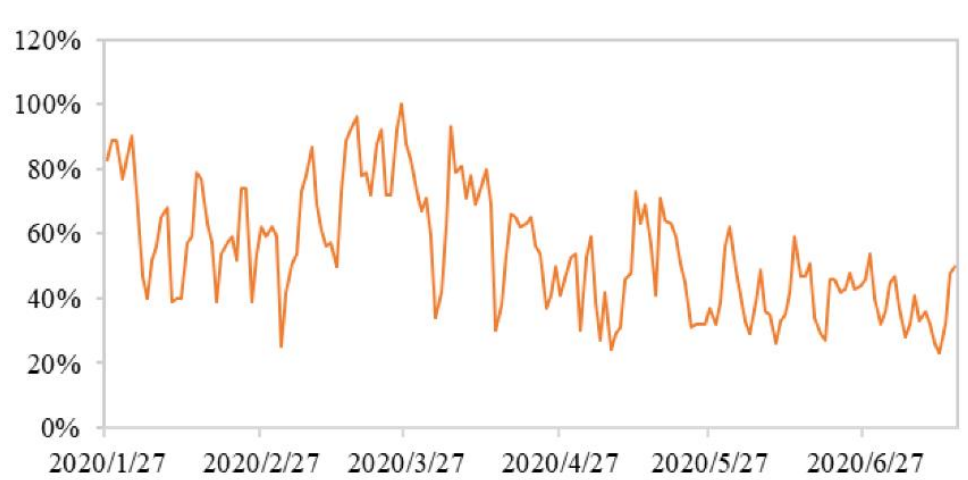

Fig. 1. The time series of the daily new confirmed cases(a), daily temperature(b), and relative humidity(c) in California, US, 2020.1.27-2020.7.15.

\subsection{Overall effects of temperature and humidity on COVID-19 transmission}

The relationship between temperature and new daily confirmed COVID-19 cases 
corresponding to the minimum COVID-19 risk. As the number of lag days increased, the effect was gradually diminishing. The overall cumulative relative risk was presented in Fig. 2b. We found that as the temperature rose, the effect gradually weakened. The RR at $6-9{ }^{\circ} \mathrm{C}$ (RR: $1.475-1.954$; CI: $1.008-3.701$ ) was statistically significant and was the maximum at $6{ }^{\circ} \mathrm{C}$ (RR: 1.954 ; CI: $\left.1.032-3.701\right)$.

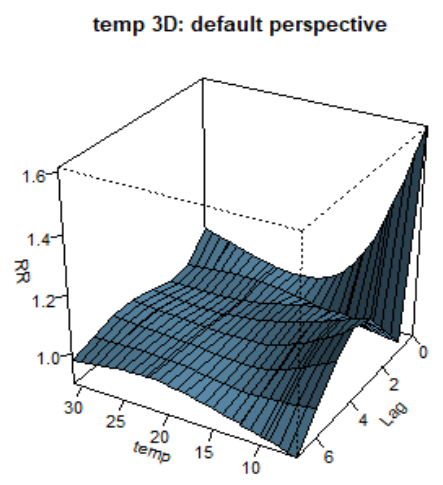

(a)

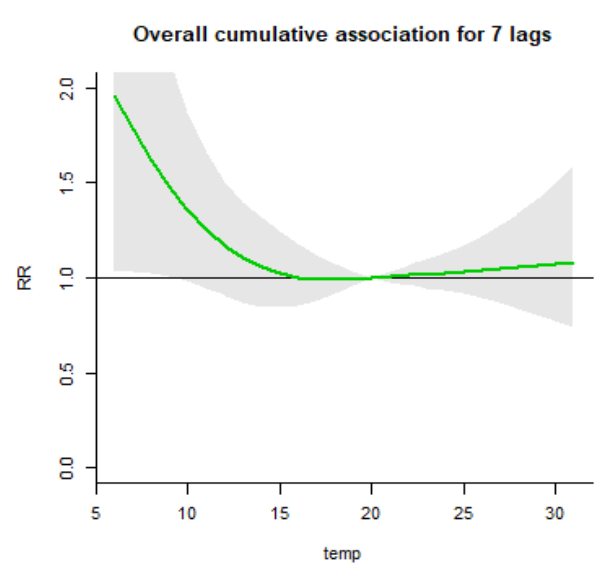

Fig. 2. Three-dimension plot and overall cumulative relative risk of daily new confirmed cases along with temperature in California, US.

The relationship between relative humidity and new daily confirmed cases was presented in Fig. 3a. There was an obvious lag effect under high humidity conditions. At $\mathrm{RH}=98 \%$, $\mathrm{Lag}=4$, the RR of relative humidity was the highest (RR: 1.094, CI: $1.015-1.177)$ compared to the reference of $60 \%$. The overall cumulative relative risk was presented in Fig. 3b. We found that as the relative humidity rose, the effect gradually strengthened. The RR for relative humidity was statistically significant from $80 \%$ to $98 \%$ (RR: $1.196-1.703$, CI: $1.019-2.765$ ) with the reference of $60 \%$, and was the maximum at $98 \%$ (RR: 1.703 , CI: $1.049-2.765)$. 
RH 3D: default perspective

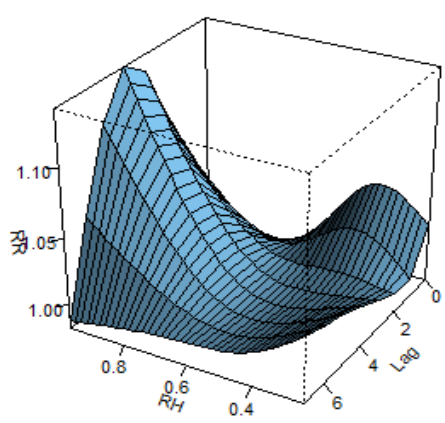

221

222

223

224

225

226

227

228

229

230

231

232

233

234

235

236

(a) along with relative humidity in California, US. transmission

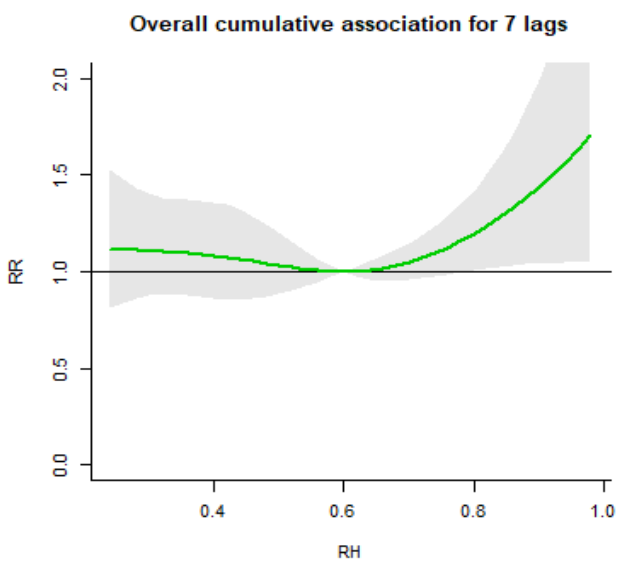

(b)

Fig. 3. Three-dimension plot and overall cumulative relative risk of daily new confirmed cases

\subsection{Delayed effects of specific temperature and humidity on COVID-19}

Delayed effects between the RRs of COVID-19 and temperature in different groups $\left(\mathrm{P} 5,9.42{ }^{\circ} \mathrm{C} ; \mathrm{P} 25,12.06{ }^{\circ} \mathrm{C} ; \mathrm{P} 75,22.34{ }^{\circ} \mathrm{C}\right.$; P95, $\left.27.95{ }^{\circ} \mathrm{C}\right)$ were presented in Fig. 4 and Table 2 respectively. With the reference of $20^{\circ} \mathrm{C}$, the single-day lagged effects of specific temperature on daily new confirmed cases were shown in Fig. 4. The single-day lagged effects of specific temperature on COVID-19 cases were not statistically significant. The cumulative lag effects of specific temperature on daily new confirmed cases were shown in Table 2. At low temperature $\left(\mathrm{P} 5: 9.42{ }^{\circ} \mathrm{C}\right)$ group, the cumulative lag effect increased the risk of COVID from lag 0-4 days $(\mathrm{RR}=1.463$, 95\%CI: 1.054-2.030) and lasted until lag 0-7 days (RR=1.423, 5\%CI:1.000-2.026).

The greatest cumulative lag effect emerged on lag 0-4 days and increased $46.3 \%$ of the risk of on daily new confirmed cases $(\mathrm{RR}=1.463,95 \% \mathrm{CI}$ : $1.054-2.030)$. 

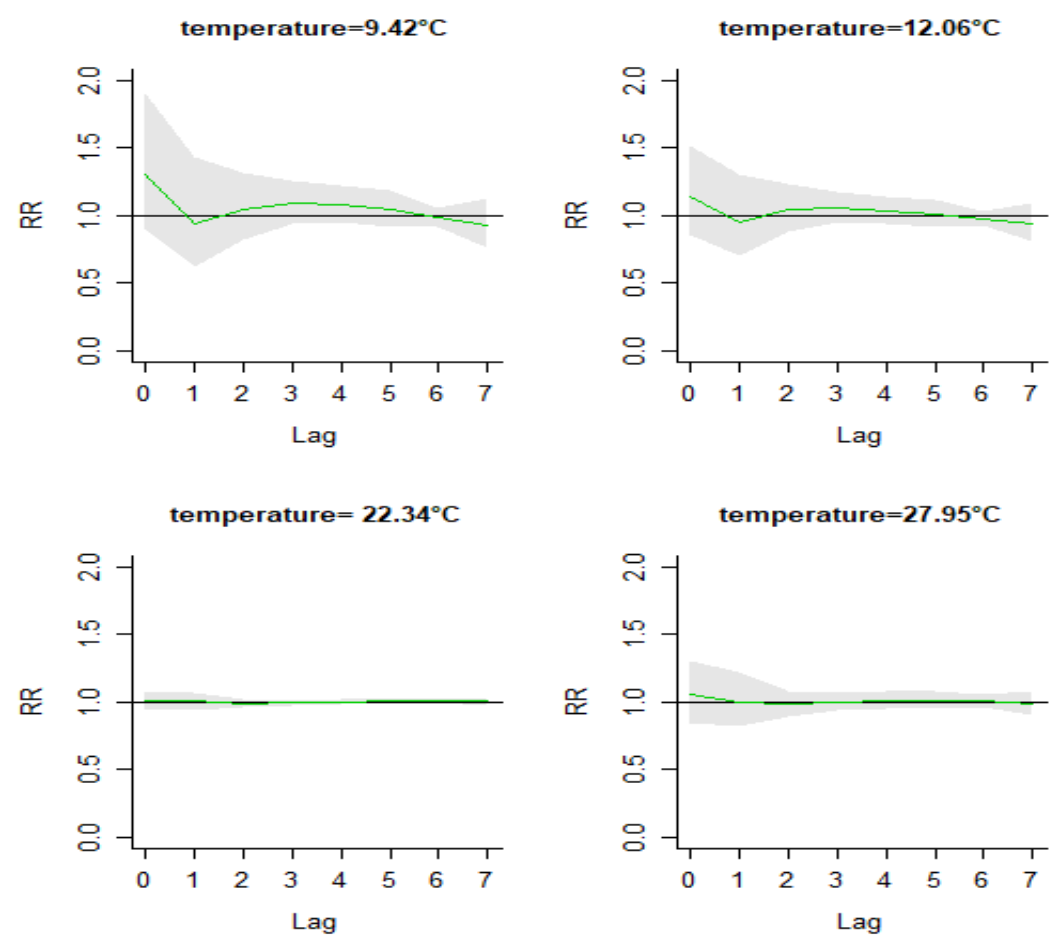

Fig. 4. single-day lagged effects of specific temperatures (P5; P25; P75; P95) on COVID-19 at various

$240 \quad$ lag times (in days), with reference of $20^{\circ} \mathrm{C}$.

241 Table 2. cumulative lag effects of specific temperatures (P5; P25; P75; P95) on COVID-19 at various

242 lag times (in days), with reference of $20^{\circ} \mathrm{C}$.

\begin{tabular}{lcrccccc}
\hline lag $\mathrm{P} 5$ & $95 \% \mathrm{CI}$ & $\mathrm{P} 25$ & $95 \% \mathrm{CI}$ & $\mathrm{P} 75$ & $95 \% \mathrm{CI}$ & $\mathrm{P} 95$ & $95 \% \mathrm{CI}$ \\
\hline $0-41.463(1.054-2.030) * 1.203(0.946-1.530)$ & $1.008(0.956-1.066)$ & $1.050 \quad(0.863-1.278)$ \\
$0-51.458(1.041-2.044) * 1.178(0.926-1.500)$ & $1.016(0.961-1.074)$ & $1.056(0.856-1.301)$ \\
$0-61.462(1.029-2.077) * 1.173(0.917-1.502)$ & $1.018(0.960-1.079)$ & $1.059(0.847-1.322)$ \\
$0-71.423(1.000-2.026) * 1.165(0.906-1.499)$ & $1.016(0.956-1.080)$ & $1.060(0.842-1.335)$
\end{tabular}


3 respectively. With the reference of $60 \%$, the single-day lagged effects of specific

humidity on daily new confirmed cases were shown in Fig. 5. At high humidity (P95: lagged effects in the other groups were not statistically significant. At high humidity (P95: 89.0\%) group, the cumulative lag effect increased the risk from lag 0-4 days (RR $=1.376,95 \% \mathrm{CI}: 1.031-1.837)$ and lasted until lag 0-7 days $(\mathrm{RR}=1.410,95 \% \mathrm{CI}: 1.040$ of the risk of on daily new confirmed cases $(\mathrm{RR}=1.423,95 \% \mathrm{CI}: 1.070-1.892)$.
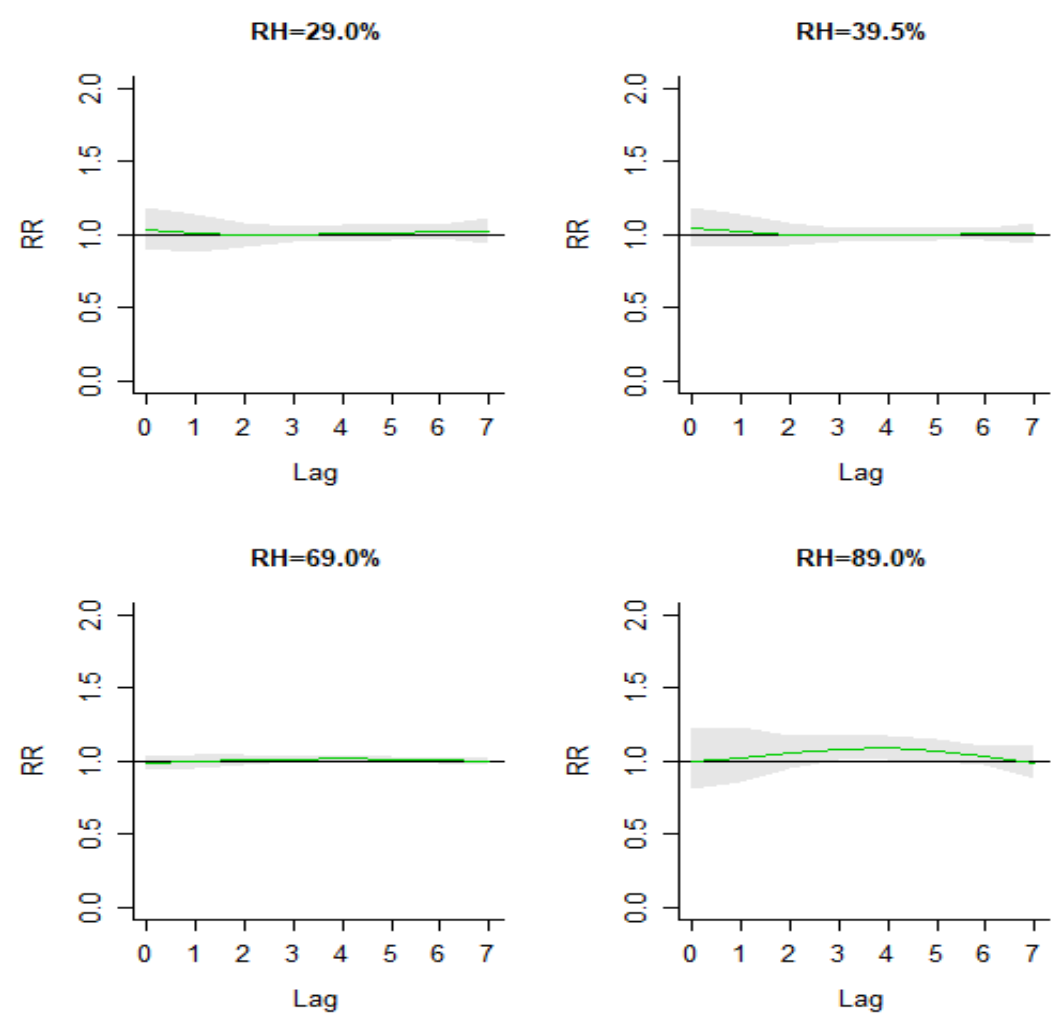
Fig. 5. single-day lagged effects of specific humidity (P5; P25; P75; P95) on COVID-19 at various lag times (in days), with reference of $60 \%$.

Table 3. cumulative lag effects of specific humidity (P5; P25; P75; P95) on COVID-19 at various lag times (in days), with reference of $60 \%$.

\begin{tabular}{lcccccccc}
\hline lag & P5 & $95 \% \mathrm{CI}$ & $\mathrm{P} 25$ & $95 \% \mathrm{CI}$ & $\mathrm{P} 75$ & $95 \% \mathrm{CI}$ & $\mathrm{P} 95$ & $95 \% \mathrm{CI}$ \\
\hline $0-4$ & $1.029(0.844-1.254)$ & $1.040(0.849-1.273)$ & $1.043(0.969-1.123)$ & $1.376(1.031-1.837) *$ \\
$0-5$ & $1.064(0.866-1.307)$ & $1.065(0.869-1.305)$ & $1.039(0.965-1.118)$ & $1.383(1.047-1.825) *$ \\
$0-6$ & $1.092(0.874-1.365)$ & $1.082(0.873-1.342)$ & $1.040(0.962-1.126)$ & $1.423(1.070-1.892) *$ \\
$0-7$ & $1.110(0.869-1.417)$ & $1.085(0.864-1.363)$ & $1.040(0.956-1.132)$ & $1.410(1.040-1.911) *$
\end{tabular}

P5; P25; P75; P95: the 5th percentile(29.0\%); the 25th percentile (39.5\%); the 75th percentil

$* \mathrm{P}<0.05$

\subsection{Sensitivity analysis}

The result of sensitivity analysis indicated that the model was robust when the dfs were altered for temperature $(\mathrm{df}=2,4)$, humidity $(\mathrm{df}=2,4)$, wind speed $(\mathrm{df}=2,4)$, time show significant differences for the fitting effect of the model either (Fig. S3, Fig. S4). The exposure-response curve was similar before and after adjusting.

\section{Discussion}

The COVID-19 pandemic is a global health crisis and the greatest challenge facing the world [17]. In this study, we examined whether temperature and humidity were 
associated with the transmission of COVID-19 in California, US. We applied the DLNM to assess the non-linear and delayed effects of temperature, humidity on COVID-19 transmission.

We found that as the temperature rose, the overall cumulative effect gradually weakened. A preprint study had a similar result using DLNM from 31 provincial-level regions in mainland China between Jan 20 and Feb 29, 2020 [4]. In our study, the RR at 6-9 ${ }^{\circ} \mathrm{C}$ had statistically significant between COVID-19 and temperature, and increased risk of illness. The RR value was maximum at $6{ }^{\circ} \mathrm{C}$, and it increased by $95.4 \%$ of the risk. Furthermore, at the low temperature $\left(9.42^{\circ} \mathrm{C}\right)$ group, the greatest cumulative lag effect emerged on lag $0-4$ days and increased $46.3 \%$ of the risk. These suggested that temperature was a risk factor under low-temperature conditions. Many previous studies supported this finding. Chin et al. reported that SARS-CoV-2 was highly stable at $4{ }^{\circ} \mathrm{C}$ but sensitive to heat. The virus survival time was shortened to $5 \mathrm{~min}$ as the incubation temperature increased to $70{ }^{\circ} \mathrm{C}[21]$. Ujiie et al. suggested that there was an association between low temperature and increased risk of COVID-19 infection [9]. Xie and Zhu also indicated that mean temperature and COVID-19 confirmed cases were the approximately positive linear relationship in the range of $<3{ }^{\circ} \mathrm{C}$, each $1{ }^{\circ} \mathrm{C}$ rose was associated with a $4.861 \%$ (95\% CI: $3.209-6.513)$ increased in the daily number of COVID-19 confirmed cases [15].

In our study, when the temperature was bigger than $10{ }^{\circ} \mathrm{C}$, we found a weaker or insignificant relationship. It indicated that the COVID-19 pandemic could not be suppressed with temperature increases. A case-crossover design with DLNM in Albany 
GA US, which median daily temperature was $18.78^{\circ} \mathrm{C}$, shown that temperature was not a significant predictor of COVID-19 cases [3]. Another study from Brazil showed across the temperature range $\left(-10^{\circ} \mathrm{C}-30^{\circ} \mathrm{C}\right)$, the researcher collected data from 429 cities around the world, divided into low-temperature group and high-temperature that the COVID-19 transmission rate was favored by higher mean temperatures $\left(27.5^{\circ} \mathrm{C}\right)[10]$. These studies supported this finding. However, in a cross-sectional study group with a limit of $10^{\circ} \mathrm{C}$. In the high-temperature group, for every $1{ }^{\circ} \mathrm{C}$ increase in temperature, the cumulative number of cases decreased by 0.86 [22]. It was inconsistent with our finding, probably because it was a time-space cross-sectional study.

We found that as the relative humidity rose, the overall cumulative effect gradually strengthened. The RR was only statistically significant from $80 \%$ to $98 \%$. It increased by $70.3 \%$ of the risk at $98 \%$. Furthermore, at high humidity $(89.0 \%)$ group, the singleday lagged effects had statistical significance from lag3 to lag5. It indicated that humidity had a certain delayed effect on COVID-19. A study on multiple cities in the United States also explored the relationship between humidity and COVID-19 cases. In the high-humidity cities of Albany and New Orleans (median the relative humidity: $9.88 \mathrm{~g} / \mathrm{kg}, 12.99 \mathrm{~g} / \mathrm{kg}$ ), there was a significant relationship between the transmission of COVID-19 and humidity. Humidity resulted in an up to the two-fold increased risk of transmission. In New York City, where the humidity is lower (median the relative humidity: $3.98 \mathrm{~g} / \mathrm{kg}$ ), no relationship was observed between humidity and COVID-19 cases [3]. This study was similar to ours that humidity was a risk factor under higher humidity conditions and there was no correlation under lower humidity conditions. 
Auler et al. also found that higher average relative humidity $(>77.7 \%)$ might favor the evolution of COVID-19 in Brazil [10].

However, some studies have reported conflicting results. Liu et al. reported that for relative humidity, the negative association with COVID-19 case counts were statistically significant in lag 7 and lag 14 [8]. Wu et al. also reported that for every $1 \%$ increase in humidity, daily new cases of COVID-19 reduced by $0.85 \%$. It might be because the research background was in cold and dry winter and the humidity range was limited [17].

The advantages of this study are as follows. First, as of July $15^{\text {th }}, 2020$, all COVID19 cases confirmed in California have been included in our study, corresponding to more meteorological data and stronger factual evidence. Second, this study was a time series analysis using DLNM, which not only allowed the model to maintain a detailed time course of the non-linear exposure-response relationship, but it also generated an estimate for the overall effect of an exposure on a health outcome over different lagged or delayed periods [19]. Third, we eliminated the long-term trend of the COVID-19 epidemic, and daily meteorological data were used to accurately reflect the effect of temperature and humidity on the transmission of COVID-19.

However, several limitations must be considered. First, we did not adjust for other environmental parameters and social factors including various interventions. Second, the impact of temperature and humidity on sex and age could not be analyzed because the key information was not available on the official website. Third, the interaction between temperature and humidity was not discussed. Qi et al. suggested 
that every $1^{\circ} \mathrm{C}$ increase in the temperature led to a decrease in the daily confirmed cases by $36 \%$ to $57 \%$ when relative humidity was in the range from $67 \%$ to $85.5 \%$ in Hubei, China [23].

\section{Conclusions}

We found that low temperature and high humidity were the risky factors of COVID-19 transmission. Higher temperature and lower humidity had no effect on COVID-19 transmission. Our results indicated that COVID-19 transmission might not slow down due to meteorological factors in summer in the Mediterranean climate.

\section{Declarations}

\section{Ethical approval and consent to participate}

Not applicable.

\section{Consent for publication}

$$
\text { Not applicable. }
$$

\section{Availability of data and material}

The datasets used and/or analyzed during the current study are available from the websites.

\section{Competing interests}

The authors declare that they have no known competing financial interests or personal relationships that could have appeared to influence the work reported in this paper.

\section{Funding}


of New Coronary Pneumonia Epidemic from China Postdoctoral Science Foundation

(2020T130001ZX), the Anhui Medical University Doctoral Research Foundation

(XJ201414), the Anhui Postdoctoral Foundation (2017B237), the National Natural

Science Foundation of China (11801010).

\section{Authors' Contribution}

Conceptualization, Lanlan Fang. and Dingjian Wang.; methodology, Lanlan Fang.; software, Dingjian Wang.; validation, Dingjian Wang.; formal analysis, Lanlan Fang.; investigation, Dingjian Wang.; resources, Lanlan Fang.; data curation, Dingjian Wang.; writing — original draft preparation, Lanlan Fang; writing — review and editing,

\section{References}

1. Boccaletti, S.; Ditto, W.; Mindlin, G.; Atangana, A. Modeling and forecasting of epidemic spreading: The case of Covid-19 and beyond. Chaos Solitons Fractals 2020, 135, 109794, doi:10.1016/j.chaos.2020.109794.

2. Tan, J.; Mu, L.; Huang, J.; Yu, S.; Chen, B.; Yin, J. An initial investigation of the association between the SARS outbreak and weather: with the view of the environmental temperature and its variation. J Epidemiol Community Health 
2005, 59, 186-192, doi:10.1136/jech.2004.020180.

3. Runkle, J.D.; Sugg, M.M.; Leeper, R.D.; Rao, Y.; Matthews, J.L.; Rennie, J.J. Short-term effects of specific humidity and temperature on COVID-19 morbidity in select US cities. Sci Total Environ 2020, 740, 140093, doi:10.1016/j.scitotenv.2020.140093.

4. Shi, P.; Dong, Y.; Yan, H.; Li, X.; Zhao, C.; Liu, W.; He, M.; Tang, S.; Xi, S. The impact of temperature and absolute humidity on the coronavirus disease 2019 (COVID-19) outbreak - evidence from China. medRxiv 2020, doi:10.1101/2020.03.22.20038919.

5. Aboubakr, H.A.; Sharafeldin, T.A.; Goyal, S.M. Stability of SARS-CoV-2 and other coronaviruses in the environment and on common touch surfaces and the influence of climatic conditions: a review. Transbound Emerg Dis 2020, 10.1111/tbed.13707, doi:10.1111/tbed.13707.

6. Chan, K.H.; Peiris, J.S.; Lam, S.Y.; Poon, L.L.; Yuen, K.Y.; Seto, W.H. The Effects of Temperature and Relative Humidity on the Viability of the SARS Coronavirus. Adv Virol 2011, 2011, 734690, doi:10.1155/2011/734690.

7. Sobral, M.F.F.; Duarte, G.B.; da Penha Sobral, A.I.G.; Marinho, M.L.M.; de Souza Melo, A. Association between climate variables and global transmission oF SARS-CoV-2. Sci Total Environ 2020, 729, 138997, doi:10.1016/j.scitotenv.2020.138997.

8. Liu, J.; Zhou, J.; Yao, J.; Zhang, X.; Li, L.; Xu, X.; He, X.; Wang, B.; Fu, S.; Niu, T., et al. Impact of meteorological factors on the COVID-19 transmission: 
A multi-city study in China. Sci Total Environ 2020, 726, 138513, doi:10.1016/j.scitotenv.2020.138513.

9. Ujiie, M.; Tsuzuki, S.; Ohmagari, N. Effect of temperature on the infectivity of COVID-19. Int J Infect Dis 2020, 95, 301-303, doi:10.1016/j.ijid.2020.04.068.

10. Auler, A.C.; Cassaro, F.A.M.; da Silva, V.O.; Pires, L.F. Evidence that high temperatures and intermediate relative humidity might favor the spread of COVID-19 in tropical climate: A case study for the most affected Brazilian $\begin{array}{lllll}\text { cities. } & \text { Sci } & \text { Total }\end{array}$ doi:10.1016/j.scitotenv.2020.139090.

11. Barreca, A.I.; Shimshack, J.P. Absolute humidity, temperature, and influenza mortality: 30 years of county-level evidence from the United States. Am J Epidemiol 2012, 176 Suppl 7, S114-122, doi:10.1093/aje/kws259.

12. Lin, K.; Yee-Tak Fong, D.; Zhu, B.; Karlberg, J. Environmental factors on the SARS epidemic: air temperature, passage of time and multiplicative effect of hospital infection. Epidemiol Infect 2006, 134, 223-230, doi:10.1017/s0950268805005054.

13. Wang, J.; McMichael, A.J.; Meng, B.; Becker, N.G.; Han, W.; Glass, K.; Wu, J.; Liu, X.; Liu, J.; Li, X., et al. Spatial dynamics of an epidemic of severe acute respiratory syndrome in an urban area. Bull World Health Organ 2006, 84, 965 968, doi:10.2471/blt.06.030247.

14. Cao, C.; Chen, W.; Zheng, S.; Zhao, J.; Wang, J.; Cao, W. Analysis of Spatiotemporal Characteristics of Pandemic SARS Spread in Mainland China. 
Biomed Res Int 2016, 2016, 7247983, doi:10.1155/2016/7247983.

15. Xie, J.; Zhu, Y. Association between ambient temperature and COVID-19 infection in 122 cities from China. Sci Total Environ 2020, 724, 138201, doi:10.1016/j.scitotenv.2020.138201.

16. Bashir, M.F.; Ma, B.; Bilal; Komal, B.; Bashir, M.A.; Tan, D.; Bashir, M. Correlation between climate indicators and COVID-19 pandemic in New York, $\begin{array}{llllll}\text { USA. } & \text { Sci Total Environ 2020, } & \text { 728, } & \text { 138835, }\end{array}$ doi:10.1016/j.scitotenv.2020.138835.

17. Wu, Y.; Jing, W.; Liu, J.; Ma, Q.; Yuan, J.; Wang, Y.; Du, M.; Liu, M. Effects of temperature and humidity on the daily new cases and new deaths of COVID-19 in 166 countries. Sci Total Environ 2020, 729, 139051, doi:10.1016/j.scitotenv.2020.139051.

18. Bhaskaran, K.; Gasparrini, A.; Hajat, S.; Smeeth, L.; Armstrong, B. Time series regression studies in environmental epidemiology. Int J Epidemiol 2013, 42, 1187-1195, doi:10.1093/ije/dyt092.

19. Gasparrini, A.; Armstrong, B.; Kenward, M.G. Distributed lag non-linear models. Stat Med 2010, 29, 2224-2234, doi:10.1002/sim.3940.

20. Liu, K.; Hou, X.; Ren, Z.; Lowe, R.; Wang, Y.; Li, R.; Liu, X.; Sun, J.; Lu, L.; Song, X., et al. Climate factors and the East Asian summer monsoon may drive large outbreaks of dengue in China. Environ Res 2020, 183, 109190, doi:10.1016/j.envres.2020.109190.

21. Chin, A.W.H.; Chu, J.T.S.; Perera, M.R.A.; Hui, K.P.Y.; Yen, H.-L.; Chan, 
M.C.W.; Peiris, M.; Poon, L.L.M. Stability of SARS-CoV-2 in different environmental conditions. The Lancet Microbe 2020, 1, doi:10.1016/s2666$5247(20) 30003-3$.

22. Wang, M.; Jiang, A.; Gong, L.; Luo, L.; Guo, W.; Li, C.; Zheng, J.; Li, C.; Yang, B.; Zeng, J., et al. Temperature Significantly Change COVID-19 Transmission in 429 cities 2020, doi:10.1101/2020.02.22.20025791.

23. Qi, H.; Xiao, S.; Shi, R.; Ward, M.P.; Chen, Y.; Tu, W.; Su, Q.; Wang, W.; Wang, X.; Zhang, Z. COVID-19 transmission in Mainland China is associated with temperature and humidity: A time-series analysis. Sci Total Environ 2020, 728, 138778, doi:10.1016/j.scitotenv.2020.138778.

\section{Figure legends}

Fig. 1. The time series of the daily new confirmed cases(a), daily temperature(b), and relative humidity(c) in California, US, 2020.1.27-2020.7.15.

Fig. 2. Three-dimension plot and overall cumulative relative risk of daily new confirmed cases along with temperature in California, US.

Fig. 3. Three-dimension plot and overall cumulative relative risk of daily new confirmed cases along with relative humidity in California, US.

Fig. 4. single-day lagged effects of specific temperatures (P5; P25; P75; P95) on COVID-19 at various lag times (in days), with reference of $20^{\circ} \mathrm{C}$.

Fig. 5. single-day lagged effects of specific humidity (P5; P25; P75; P95) on COVID19 at various lag times (in days), with reference of $60 \%$. 
475 Fig. S1. exposure-response diagram under different df $(2,4)$ between temperature and 476 COVID-19.

477 Fig. S2. exposure-response diagram under different df $(2,4)$ between humidity and 478 COVID-19.

479 Fig. S3. exposure-response diagram under between temperature, humidity, and 480 COVID-19 when the maximum number of lag days is 6.

481 Fig. S4. exposure-response diagram under between temperature, humidity, and 482 COVID-19 when the maximum number of lag days is 8 . 


\section{Figures}

new confirmed cases (a)
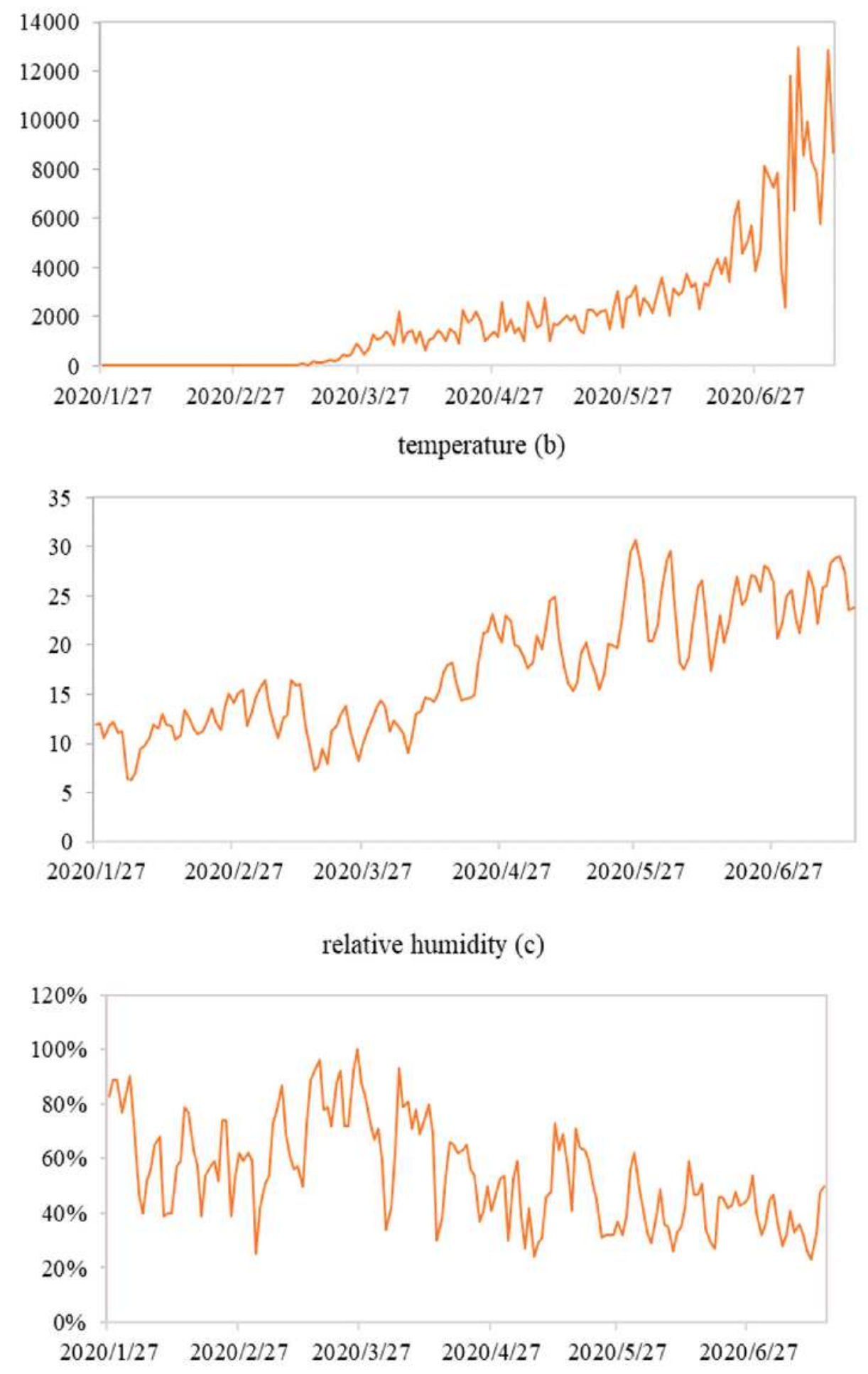

Figure 1

The time series of the daily new confirmed cases(a), daily temperature(b), and relative humidity(c) in California, US, 2020.1.27-2020.7.15. 
temp 3D: default perspective

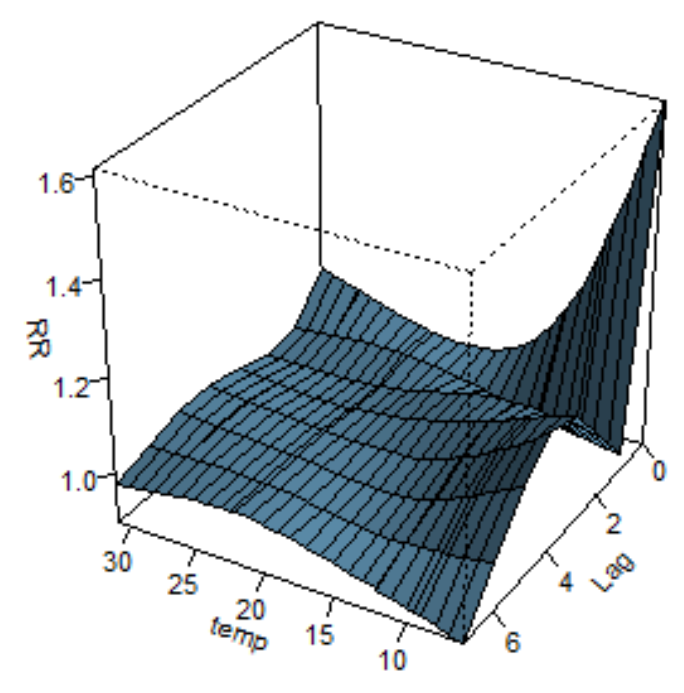

Overall cumulative association for 7 lags

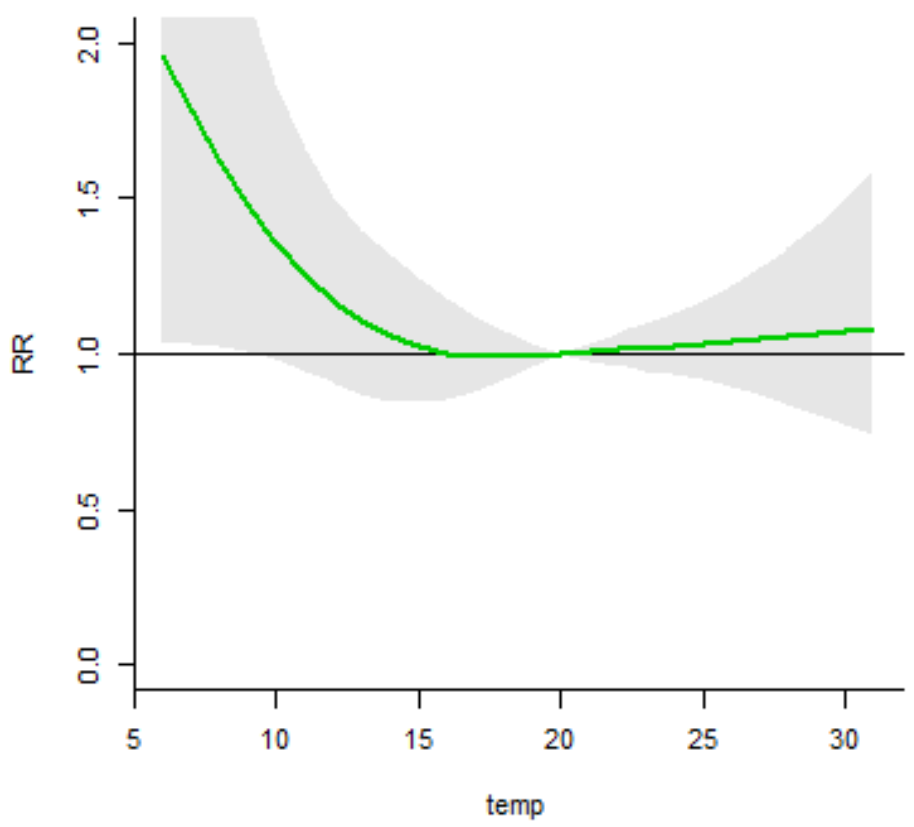

Figure 2

Three-dimension plot and overall cumulative relative risk of daily new confirmed cases along with temperature in California, US.

RH 3D: default perspective

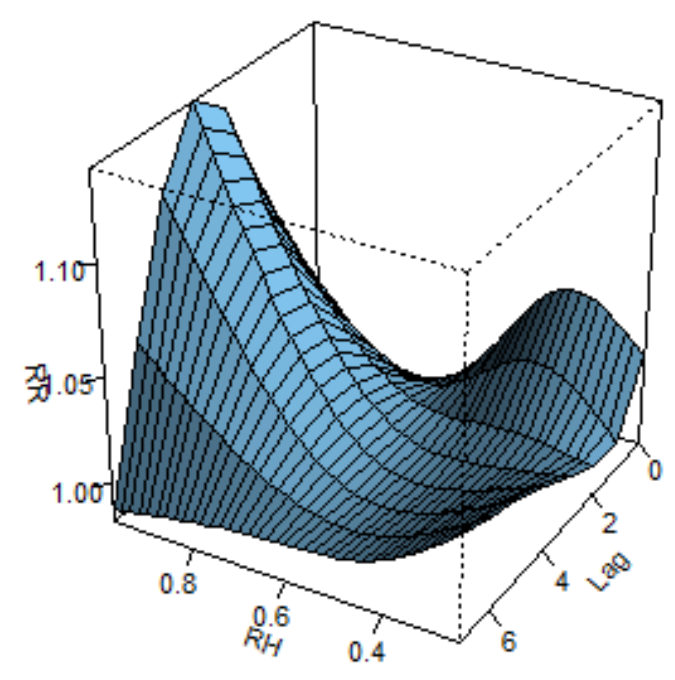

Overall cumulative association for 7 lags

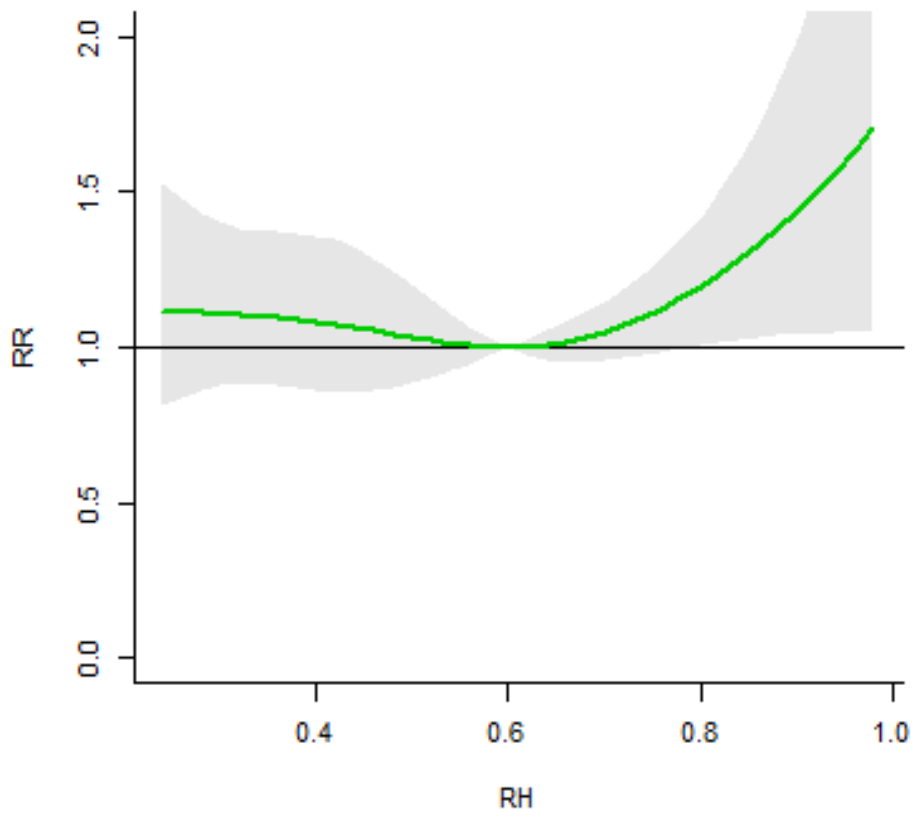

\section{Figure 3}


Three-dimension plot and overall cumulative relative risk of daily new confirmed cases along with relative humidity in California, US.
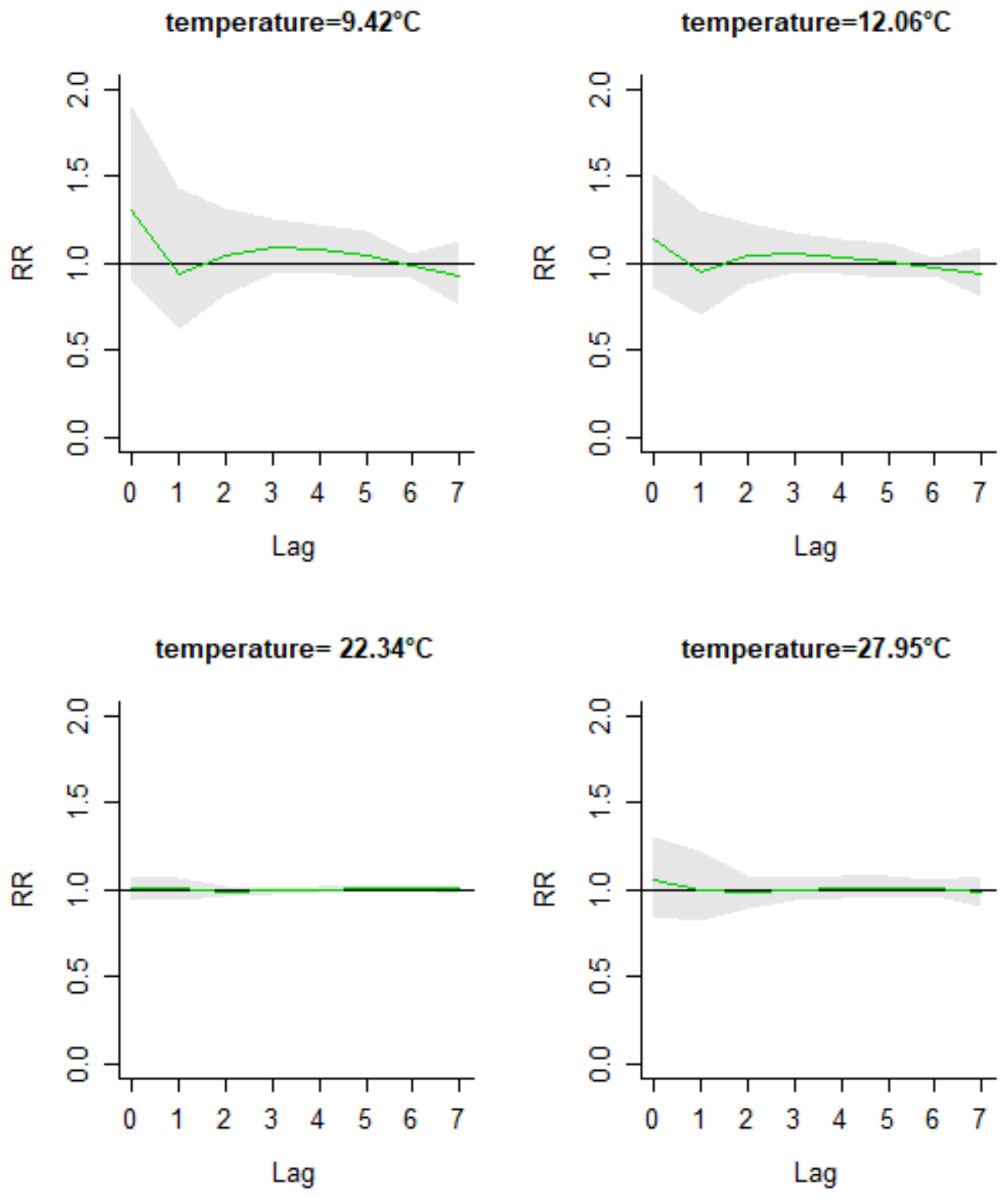

\section{Figure 4}

single-day lagged effects of specific temperatures (P5; P25; P75; P95) on COVID-19 at various lag times (in days), with reference of $20^{\circ} \mathrm{C}$. 
$\mathrm{RH}=\mathbf{2 9 . 0} \%$

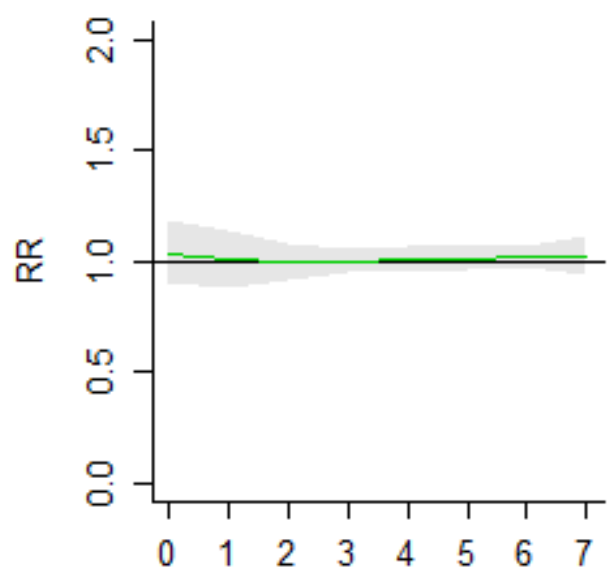

Lag

$\mathrm{RH}=69.0 \%$

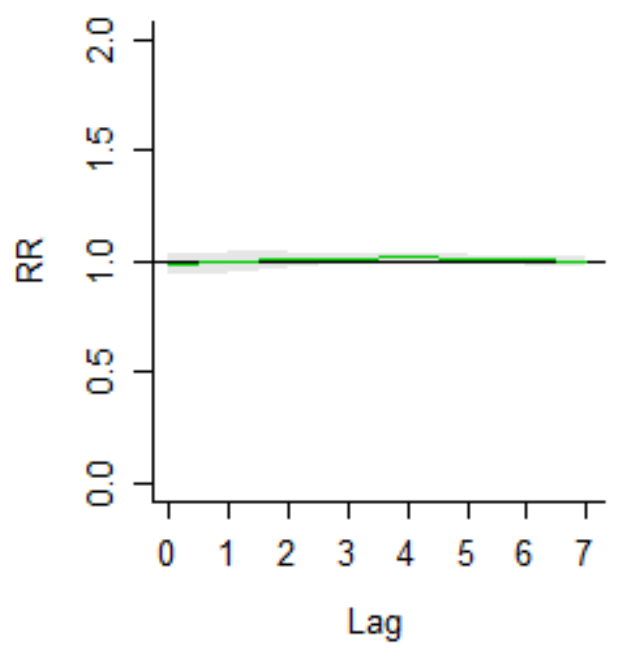

$\mathrm{RH}=39.5 \%$

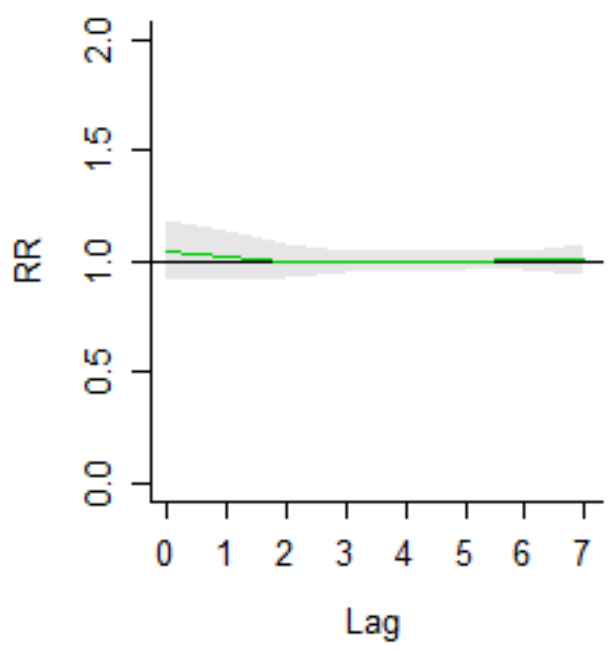

$\mathrm{RH}=89.0 \%$

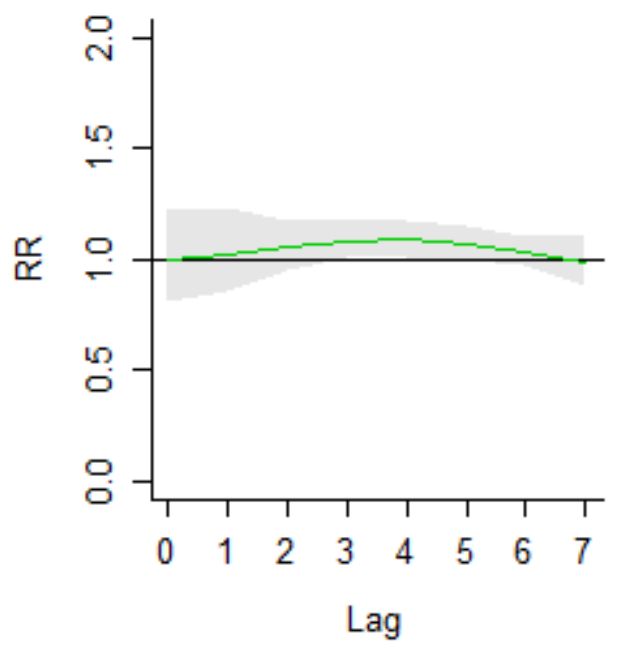

\section{Figure 5}

single-day lagged effects of specific humidity (P5; P25; P75; P95) on COVID-19 at various lag times (in days), with reference of $60 \%$.

\section{Supplementary Files}

This is a list of supplementary files associated with this preprint. Click to download.

- Fig.docx 